\title{
Clusters of multimorbidity across hospital services and by language groups
}

\author{
Eva Guérin*1 , El Mostafa Bouattane ${ }^{1,2}$, John Joanisse ${ }^{1,2}$, Denis Prud'homme ${ }^{1,3}$ \\ ${ }^{1}$ Institut du Savoir Montfort, Ottawa, Canada \\ ${ }^{2}$ Hôpital Montfort, Ottawa, Canada \\ ${ }^{3}$ School of Human Kinetics, University of Ottawa, Ottawa, Canada
}

Received: January 30, 2021

DOI: $10.5430 /$ jha.v10n1p6

\author{
Accepted: February 17, 2021 \\ Online Published: February 24, 2021
}

\begin{abstract}
Objective: Documenting multimorbidity profiles and resource use across hospital sectors can help inform and improve healthcare delivery. The purpose of this cohort study (2013-2017) was to describe profiles of multimorbidity among patients at an acute care hospital in Ontario, Canada.

Methods: This was a retrospective cohort study over five fiscal years. Data from patients who were admitted as inpatients, visited the emergency department (ED), or received day surgeries at an acute care hospital in Ottawa, Canada between 2013 and 2017 were obtained from two individual-level administrative databases. Diagnoses for 13 chronic diseases and clusters of multimorbidity were identified using validated methods. The analysis sample was comprised of 22,932 patients with multimorbidity aged 18 years or over. Demographic (e.g., age) and clinical (e.g., ED visit count) characteristics of chronic disease clusters were examined across inpatient, ED, and day surgery services, and between language groups.

Results: The most common disease profiles encompassed hypertension, diabetes, and arthritis. Mental health and mood conditions were highly concomitant among ED patients. Degree of multimorbidity was significantly associated with length of stay (LOS) and frequency of ED visits. Compared to Anglophone inpatients, hospitalized Francophone patients had significantly more comorbid conditions.

Conclusions: Treatment plans should be tailored for different types of hospital services and will need to be patient-centered to account for variability in disease clusters, sociodemographic factors, and acuity levels. More studies are needed to understand the impacts of multimorbidity on healthcare systems.
\end{abstract}

Key Words: Multimorbidity, Chronic disease, Acute care, Hospitalization, Emergency department, Language

\section{INTRODUCTION}

\subsection{The burden of multimorbidity}

With the global increase in average life expectancy, the prevalence rate of living with one or more chronic disease(s) throughout the lifespan has increased dramatically. ${ }^{[1]}$ There is growing indication that multimorbidity, defined as the presence of two or more concurrent chronic disease, is a considerable challenge to healthcare systems and an important threat to public health. ${ }^{[2-4]}$ Multimorbidity has been linked to a multitude of far-reaching implications and is associated with considerable economic strain and worse clinical outcomes. ${ }^{[5,6]}$ The burden of multimorbidity is expected to grow exponentially with time..$^{[7,8]}$

\footnotetext{
*Correspondence: Eva Guérin; Email: eva.eg.guerin@gmail.com; Address: : Institut du Savoir Montfort, 202-745A Montréal Rd., Ottawa ON, K1K 0T1, Canada.
} 
In Canada, the prevalence of multimorbidity varies between studies. Data from the 2011/12 Canadian Community Health Survey revealed that $12.9 \%$ of Canadians report two or more chronic diseases and $3.9 \%$ report three or more. ${ }^{[9]}$ From administrative health data for five specific conditions (i.e., cardiovascular disease, respiratory disease, mental illness, hypertension, diabetes), including data from the validated Canadian Chronic Disease Surveillance System (CCDSS), the prevalence of two or more- and three or more-chronic diseases among those aged 40 years and over was estimated at $26.5 \%$ and $10.2 \%$, respectively. ${ }^{[10]}$ In a study in the province of Ontario, the prevalence of multimorbidity rose by $\%$ between 2003 and 2009 to $24.3 \%$. ${ }^{[3]}$

\subsection{Multimorbidity in the hospital setting}

Discrepancies in terms of prevalence and patterns of multimorbidity arise based on methodological aspects, including the type of population and documentation methods (e.g., general population self-reporting vs. health administrative data from patients seeking care). ${ }^{[11]}$ In addition, there is significant heterogeneity in terms of how multimorbidity is defined and how chronic conditions themselves are classified (and divided), as well as in how the chronicity of specific diseases is determined. ${ }^{[12]}$ Diseases that are routinely examined in studies reporting the prevalence of multimorbidity include diabetes, hypertension and chronic obstructive pulmonary disease (COPD), ${ }^{[13]}$ while others such as mental illness, depression, asthma, and various inflammatory diseases are not consistently documented. ${ }^{[11,12,14]}$

Most studies to date in Canada, and in other developed countries, have been conducted using health administrative records in primary care, namely health practitioner records and billing information, or using population health surveys and self-reported data. ${ }^{[9,15-18]}$ However, studies pertaining to the prevalence and management of multimorbidity in hospital settings remain scarce. ${ }^{[17,19]}$ Schneider et al. ${ }^{[17]}$ showed that administrative discharge data is a suitable source of data to describe multimorbidity in the hospital setting, where many patients are likely to have multiple chronic diseases that may or may not be directly related to the reason for their admission. ${ }^{[19,20]}$ Similarly, records and diagnostics stemming from emergency department (ED) visits can offer useful insights regarding multimorbidity and healthcare utilization in the acute care context. ${ }^{[21,22]}$ For acute care facilities, adequately documenting multimorbidity patterns among patients and their service use across sectors (i.e., ambulatory vs. hospitalization) can help inform and improve models of healthcare delivery. ${ }^{[22]}$ Better approaches to managing patients with chronic diseases in inpatient facilities can improve healthcare efficiency, help to achieve more coordinated outpatient

Published by Sciedu Press care, and lead to improvements in health outcomes and quality of life. ${ }^{[19]}$ Few hospital studies have been conducted to describe the clinical profile of patients with multimorbidity across inpatient, emergency, and ambulatory (i.e., day surgery) services.

\subsection{The context of multimorbidity}

The administration of healthcare to patient with multimorbidity is affected by the social, educational, cultural, and environmental circumstances within which the burden of multimorbidity develops for each patient. ${ }^{[23]}$ In the US, for example, the prevalence of multiple chronic medical conditions is associated with race and ethnicity (e.g., higher in African Americans). ${ }^{[24]}$ The individual context and cultural needs of patients should be considered to better understand the intersection of diseases and how to deliver care appropriately. To broaden our understanding of vulnerable populations when it comes to patients with multimorbidity, more research is needed to address population characteristics across social, cultural, and economic dimensions. ${ }^{[24,25]}$

Canada has a unique sociopolitical context in that it has two Official Languages: English and French. The province of Ontario has the second highest proportion of Francophones, after Quebec. ${ }^{[26]}$ The majority of Francophones in Ontario live in a linguistic-minority situation and they have a tendency to be older and of lower socioeconomic status. ${ }^{[27,28]}$ Studies have identified a greater health risk in the Francophone population in Ontario compared to Anglophones and Allophones, including higher rates of obesity and a significantly higher prevalence of chronic diseases, such as cardiovascular diseases, pulmonary diseases, arthritis, and rheumatism. ${ }^{[29,30]}$ Roberts et al. ${ }^{[9]}$ found that Canadians who report three or more chronic diseases are more likely to be female, older, and of lower educational status and income, although they did not examine language as a risk factor. To our knowledge, no study has examined multimorbidity profiles by language groups in Canada.

\subsection{Purpose of the study}

The overall purpose of this study was to identify and describe profiles of multimorbidity for patients visiting a bilingual acute care hospital in Ottawa, Ontario, Canada. Specifically, the goal was to examine demographic and clinical characteristics, as well as clusters of chronic diseases, for patients with multimorbidity (i.e., two or more chronic diseases) across three services of care: inpatient, ED, and day surgery.

A secondary objective was to examine the influence of language group, namely French, English and other (Allophones), on clinical characteristics and clusters of multimorbidity, including degree of multimorbidity (i.e., number of condi- 
tions).

\section{MeTHODS}

\subsection{Study design \& setting}

This was a retrospective cohort study over five fiscal years (2013-2017). We used linked health administrative data for patients aged 18 years or over who visited an academic acute care hospital in Ottawa, Canada. With just under 300 beds, this hospital delivers short-term primary and secondary healthcare to residents of Eastern Ontario in both official languages (English, French). The study protocol was approved by the hospital's research ethics board.

\subsection{Data sources}

Data were obtained from two encrypted, individual-level administrative databases populated by the Canadian Institute for Health Information: the Hospital Discharge Abstract Database (DAD) and the National Ambulatory Care Reporting System (NACRS). The DAD is comprised of administrative, clinical, and demographic data from all inpatient discharges (including deaths, sign-outs and transfers); hospital programs that are housed in separate databases (e.g., Ontario Mental Health Reporting System [OMHRS]) are excluded from DAD. The NACRS database contains patient ambulatory data collected at the time of service for day surgeries and ED visits. Language was determined using routinely collected data from all patients during registration at the hospital [i.e., "What is your first language (mother tongue)?")] The data were linked using unique coded identifiers and maintained on a secure hospital server where the data were analyzed.

\subsection{Definitions}

The approach used to determine the presence of multiple chronic diseases was consistent with established and validated methods used in other studies using health administrative data in Canada. ${ }^{[3,16,31]}$ We initially examined the type of diagnostic code associated with each diagnosis, which reflects the impact of the condition on patient care. For DAD and NACRS, we considered all Main Diagnoses, all listed comorbidity codes and secondary diagnoses, as well as any service transfer diagnosis. Diagnostic codes associated with morphology, newborn, and external cause of injury were excluded.

The 13 chronic diseases considered in this study are listed in Tables 1 and 2. Crohn's disease, obesity, and sleep apnea were uniquely considered in this study based on their estimated burden for patients served by this hospital. Diagnoses were identified using an established list of ICD-10-CA (International Statistical Classification of Diseases and Related
Health Problems, 10th Revision, Canada) codes supported by both the DAD and NACRS. The complete list of diagnostic codes used in this study are available in Appendix A.

Patients were initially identified on the basis of at least one documented chronic disease as of April 1, 2013. The final analysis cohort was established on the basis of multimorbidity, defined as two or more coexisting chronic diseases. Given heterogeneity in methods used to establish meaningful clusters in the literature, particularly in the absence of an index disease, we used a basic count of the number of chronic diseases. ${ }^{[16]}$ Two approaches were used to describe the most common clusters: 1) Final groupings (i.e., patient presents with only the identified diseases; and 2) Minimal groupings (i.e., patient present with at least the identified diseases, with or without additional diagnoses).

Demographic characteristics such as age were extracted from a patient's first appearance in the linked dataset (baseline). The total number of hospitalizations (i.e., inpatient admissions) and visits (i.e., ED and day surgery), as well as the average acute length of stay (LOS) for inpatients, were computed over the full study period for the final cohort of patients with multimorbidity. Computations were based on all available data, even if one of the identified chronic conditions was not documented during a particular visit or admission.

\subsection{Analyses}

Descriptive statistics for demographic variables, chronic diseases, and clinical indicators were described by service type (i.e., inpatient, ED, day surgery) and by language group (French, English, and Allophone). Count and binary variables were reported using frequencies and proportions; means and standard deviations $(S D, \pm)$ were computed for continuous variables. Given overlap regarding the type of care received by each patient (i.e., use of inpatient and ED services), differences between services were not analyzed statistically. Differences between language groups for count and binary variables were examined using chi-square tests of association with follow-up Mann-Whitney $U$ tests to examine pair-wise differences. Continuous variables were compared using ANOVAs with post-hoc $t$-tests.

For patients with multimorbidity, we used generalized linear model (GLM) regressions with a log link function and negative binomial distribution to estimate the association of age, gender, and language with the number of chronic diseases (i.e., degree of multimorbidity), independently for inpatients (at least one admission) and ED patients (at least one visit). We further examined the influence of language group and degree of multimorbidity on a) LOS (inpatients) and b) frequency of ED visits using multiple regression and GLM (negative binomial distribution), respectively (adjust- 
ing for age and gender). Significance was set at $p<.05$ and a Bonferroni correction was applied for post-hoc comparisons. Analyses were conducted using SAS Enterprise Guide 7.1.

\section{Results}

\subsection{Characteristics of patients with multimorbidity by type of service}

Out of 59,288 patients with at least one documented chronic disease between 2013 and 2017, 22,932 (38.7\%) were classified as having multimorbidity and were included in the analysis cohort. Table 1 presents a breakdown of demographic factors, service utilization, and chronic disease prevalence by service. Across services, the average number of chronic diseases per patient was just over three (median $=3$; range: 2 15). Patients with multimorbidity ranged in age from 63.83 (ED) to 68.43 (inpatient), and just over half were female. Language groups were similarly distributed across ED and inpatients, with 50\% reporting French as their mother tongue and approximately $8 \%$ reporting other languages. The most common chronic diseases across all patients with multimorbidity were hypertension and diabetes, and the least common were rheumatoid arthritis and Crohn's disease.

Among inpatients, nearly three-quarters (73.0\%) of patients suffered from two or more chronic diseases. Consistent with the level of care required, the proportion of inpatients reporting six or more chronic diseases $(8.1 \%)$ was more than double that of ED patients $(3.9 \%)$. The most prevalent chronic disease was hypertension, affecting $62.6 \%$ of multimorbid inpatients, followed by diabetes $(36.4 \%)$ and arthritis $(34.8 \%)$. Over the 5-year study period, there were a total of 27,664 hospitalizations for this group (5,533 per year), with an average of two hospitalizations per patient and an average LOS of 6.73 days ( \pm 7.99 ). There were approximately 300 documented deaths per year among inpatients with multimorbidity, representing approximately $9 \%$ of patients.

Data from ED visits revealed that $41.2 \%$ of patients had two or more chronic diseases. The prevalence of two diseases per patient was $19.6 \%$, dropping to less than $10 \%$ for three, four, five, and six or more diseases. For multimorbid patients visiting the ED, rates of hypertension and diabetes were $48.2 \%$ and $38.3 \%$ respectively. Mental illness (31.5\%) was also highly prevalent among ED patients, as were arthritis $(29.3 \%)$ and mood disorders $(26.1 \%)$. The total number of ED visits generated by patients with multimorbidity was 73 543 , with an average of 3.81 ED visits per patient. Roughly two-thirds of patients with multimorbidity (65.4\%) had been admitted in hospital from the ED at least once, although only $29.4 \%$ of all ED visits from patients in this cohort resulted in an admission. The crude mortality rate for ED patients with multimorbidity $(7.7 \%)$ was similar to that of inpatients Published by Sciedu Press
$(8.8 \%)$.

For patients who had received day surgeries, the prevalence of multimorbidity was lower than other services at only $35.1 \%$, and almost half $(46.1 \%)$ of those patients had only two chronic diseases. Only $2.6 \%$ of all day surgery patients were classified as having five diseases, rising slightly to $3.1 \%$ for six or more diseases ( $8.9 \%$ of those with multimorbidity). More than half of day surgery patients suffered from hypertension $(58.6 \%)$, while diabetes and arthritis were equally widespread $(41.0 \%)$ and also higher compared to other services. The prevalence of cancer was also higher at $20.1 \%$. Patients recorded a total of 13,937 day surgeries over the study period, with an average of two surgical events per patient. There was a higher proportion of Francophone patients with multimorbidity receiving day surgeries $(56.6 \%)$ compared to Anglophone (36.1\%).

\subsection{Clusters of multimorbidity}

For all patients with multimorbidity, the most common configuration of diseases encompassed hypertension, diabetes, and arthritis (see Figure 1). Specifically, hypertension with diabetes was the most common cluster $(\mathrm{N}=4,763 ; 20.8 \%)$, and only $15 \%$ of patients in this cluster presented no other chronic disease. For patients with hypertension and arthritis (Cluster 2; $\mathrm{N}=4,088 ; 17.8 \%$ ), $75 \%$ of patients were identified as having at least one other chronic disease, which was slightly higher (i.e., 69\%) than those affected by diabetes and arthritis (Cluster $3 ; \mathrm{N}=2,624 ; 11.4 \%)$. For Cluster $4(\mathrm{~N}$ $=2,982 ; 13.0 \%$ ), only $42 \%$ of patients with mental illness and a mood disorder had another chronic disease.

Patterns and degree of comorbidity varied by service type (see Figure 2). Clusters 1 and 2 were more common among inpatient and day surgery patients, although inpatients were slightly more likely to present with additional chronic diseases. Among inpatients, arthritis and diabetes (Cluster 3) rarely occurred without another disease. A fifth cluster of hypertension and renal failure was observed among inpatients $(\mathrm{N}=2,495 ; 14.7 \%)$ and ED patients $(\mathrm{N}=2,448 ; 12.7 \%)$. This cluster often occurred with other chronic diseases, particularly diabetes (50\% for ED and inpatient) and congestive heart failure (CHF; 39\% of inpatients).

Unique to ED patients was the high prevalence of Cluster 4 (mental health/mood conditions) compared to inpatients and day surgery patients, with only a third of ED patients in Cluster 4 presenting with additional diseases. Overall, the proportion of day surgery patients presenting with only the defining diseases in a cluster was slightly higher compared to inpatients and generally lower than ED patients. Finally, a unique but smaller cluster of hypertension and cancer (Cluster $6, \mathrm{~N}=829 ; 12.0 \%$ ) emerged among day surgery patients. 
Table 1. Descriptive statistics for patients with multimorbidity by hospital service ( $\mathrm{N}=59,288$ unique patients)

\begin{tabular}{|c|c|c|c|c|c|c|}
\hline \multirow{2}{*}{ Variables } & \multicolumn{2}{|c|}{ ED } & \multicolumn{2}{|c|}{ Inpatient (hospitalisations) } & \multicolumn{2}{|c|}{ Day surgery } \\
\hline & $\mathbf{N}$ (mean) & $\%(S D)$ & $\mathbf{N}$ (mean) & $\%(S D)$ & $\mathrm{N}$ (mean) & $\%(S D)$ \\
\hline \multicolumn{7}{|l|}{ Chronic conditions-count } \\
\hline $1^{1}$ & 27,503 & $58.8 \%$ & 6,270 & $27.0 \%$ & 12,834 & $64.9 \%$ \\
\hline 2 & 9,160 & $19.6 \%$ & 6,160 & $26.5 \%$ & 3,197 & $16.2 \%$ \\
\hline 3 & 4,326 & $9.4 \%$ & 4,479 & $19.3 \%$ & 1,661 & $8.4 \%$ \\
\hline 4 & 2,545 & $5.4 \%$ & 2,827 & $12.2 \%$ & 938 & $4.7 \%$ \\
\hline 5 & 1,456 & $3.1 \%$ & 1,623 & $7.0 \%$ & 513 & $2.6 \%$ \\
\hline $6+$ & 1,819 & $3.9 \%$ & 1,875 & $8.1 \%$ & 619 & $3.1 \%$ \\
\hline Multimorbidity (2+) & 19,306 & $41.2 \%$ & 16,964 & $73.0 \%$ & 6,928 & $35.1 \%$ \\
\hline Total per patient & 3.18 & 1.59 & 3.43 & 1.63 & 3.18 & 1.56 \\
\hline Age (baseline) & 63.83 & 19.04 & 68.43 & 15.75 & 65.03 & 13.74 \\
\hline \multicolumn{7}{|l|}{ Gender } \\
\hline Female & 10,111 & $52.4 \%$ & 9,065 & $53.4 \%$ & 3,398 & $49.0 \%$ \\
\hline \multicolumn{7}{|l|}{ Language } \\
\hline Francophone & 9,529 & $49.6 \%$ & 8,273 & $48.9 \%$ & 3,916 & $56.6 \%$ \\
\hline Anglophone & 8,091 & $42.1 \%$ & 7,345 & $43.5 \%$ & 2,497 & $36.1 \%$ \\
\hline Allophone (other) & 1,607 & $8.4 \%$ & 1,284 & $7.6 \%$ & 502 & $7.2 \%$ \\
\hline \multicolumn{7}{|l|}{ ED visits (5 years) } \\
\hline $\mathrm{N}$ & 19,306 & $100 \%$ & 13,579 & $80.1 \%$ & 5,557 & $80.2 \%$ \\
\hline Count total & 73,543 & - & 51,881 & - & 23,481 & - \\
\hline Count per patient & 3.81 & 4.69 & 3.82 & 4.72 & 4.23 & 5.10 \\
\hline \multicolumn{7}{|l|}{ Day surgery (5 years) } \\
\hline $\mathrm{N}$ & 5,557 & $28.8 \%$ & 5,463 & $32.2 \%$ & 6,928 & $100 \%$ \\
\hline Count total & 11,135 & - & 11,156 & - & 13,937 & - \\
\hline Count per patient & 2.00 & 1.90 & 2.04 & 1.95 & 2.01 & 1.91 \\
\hline Admitted $\geq 1$ time $^{2}$ & 12,626 & $65.4 \%$ & 11,707 & $69.0 \%$ & 3,569 & $51.5 \%$ \\
\hline \multicolumn{7}{|l|}{ Hospitalizations ( 5 years) } \\
\hline $\mathrm{N}$ & 13,579 & $70.3 \%$ & 16,964 & $100 \%$ & 5,463 & $78.9 \%$ \\
\hline Count total & 23,560 & - & 27,664 & - & 9,539 & - \\
\hline Count per patient & 1.74 & 1.35 & 1.63 & 1.25 & 1.75 & 1.31 \\
\hline Average acute LOS per admission (days) & 7.49 & 7.65 & 6.73 & 7.99 & 5.49 & 5.96 \\
\hline Death (5 years) & 1,483 & $7.7 \%$ & 1,492 & $8.8 \%$ & 295 & $4.3 \%$ \\
\hline \multicolumn{7}{|l|}{ Chronic conditions- type } \\
\hline AMI & 1,104 & $5.7 \%$ & 1,079 & $6.4 \%$ & 289 & $4.2 \%$ \\
\hline Arthritis & 5,664 & $29.3 \%$ & 5,900 & $34.8 \%$ & 2,834 & $40.9 \%$ \\
\hline Asthma & 791 & $4.1 \%$ & 691 & $4.1 \%$ & 324 & $4.7 \%$ \\
\hline Cancer & 2,266 & $11.7 \%$ & 2,415 & $14.2 \%$ & 1,393 & $20.1 \%$ \\
\hline Cardiac arrhythmia & 3,611 & $18.7 \%$ & 3,474 & $20.5 \%$ & 1,118 & $16.1 \%$ \\
\hline $\mathrm{CHF}$ & 2,781 & $14.4 \%$ & 2,718 & $16.0 \%$ & 694 & $10.0 \%$ \\
\hline COPD & 3,126 & $16.2 \%$ & 2,975 & $17.5 \%$ & 1,008 & $14.5 \%$ \\
\hline Coronary syndrome & 2,861 & $14.8 \%$ & 2,763 & $16.3 \%$ & 911 & $13.1 \%$ \\
\hline Crohn's disease & 209 & $1.1 \%$ & 170 & $1.0 \%$ & 160 & $2.3 \%$ \\
\hline Dementia & 2,370 & $12.3 \%$ & 2,315 & $13.6 \%$ & 401 & $5.8 \%$ \\
\hline Diabetes & 7,398 & $38.3 \%$ & 6,180 & $36.4 \%$ & 2,848 & $41.1 \%$ \\
\hline Hypertension & 9,302 & $48.2 \%$ & 10,612 & $62.6 \%$ & 4,058 & $58.6 \%$ \\
\hline Mental illness & 6,079 & $31.5 \%$ & 3,791 & $22.3 \%$ & 1,148 & $16.6 \%$ \\
\hline Mood disorder & 5,029 & $26.0 \%$ & 2,494 & $14.7 \%$ & 1,193 & $17.2 \%$ \\
\hline Obesity & 1,812 & $9.4 \%$ & 2,801 & $16.5 \%$ & 1,026 & $14.8 \%$ \\
\hline Osteoporosis & 438 & $2.3 \%$ & 496 & $2.9 \%$ & 131 & $1.9 \%$ \\
\hline Renal failure & 3,842 & $19.9 \%$ & 3,769 & $22.2 \%$ & 1,088 & $15.7 \%$ \\
\hline Rheumatoid arthritis & 163 & $0.8 \%$ & 179 & $1.1 \%$ & 72 & $1.0 \%$ \\
\hline Sleep apnea & 1,477 & $7.7 \%$ & 2,382 & $14.0 \%$ & 1,051 & $15.2 \%$ \\
\hline Stroke & 1,160 & $6.0 \%$ & 1,056 & $6.2 \%$ & 283 & $4.1 \%$ \\
\hline
\end{tabular}

Note. $\mathrm{N}=$ Number of patients (cases); Count $=$ Number of events; $\mathrm{LOS}=$ Length of stay; ED = Emergency department; Avg = Average; AMI = Acute myocardial infarction; CHF = Congestive heart failure; $\mathrm{COPD}=$ Chronic obstructive pulmonary disease. The denominator for the proportions in each column, with the exception of chronic condition count, is the total number of patients with multimorbidity in each sector (bold font). Databases were cross referenced to capture data for each patient across services. ${ }^{1}$ Patients with a single chronic condition were excluded from all other variable statistics and analyses in this table, with the exception of disease count proportions. ${ }^{2}$ Admitted $\geq 1$ times as inpatient from ED or day surgery; this value was taken from the NACRS database and is distinct from the number of hospitalizations extracted from DAD 


\subsection{Clinical characteristics by language groups}

Differences in the healthcare profiles of patients with multimorbidity across language groups are shown in Table 2. Francophones presented with a significantly greater degree of multimorbidity compared to Anglophones and Allophones. Anglophones had the lowest proportion of visits to the ED $(81.1 \%)$, though the number of ED visits per patient was not significantly different. Francophone patients had a higher rate of day surgeries (35.6\%) than Allophone (27.0\%) and Anglophone $(25.0 \%)$ patients. The proportion of hospitalized inpatients with multimorbidity was significantly different between language groups, with Francophones having the highest rate of hospitalizations per patient. There were no significant unadjusted differences in the average acute LOS in days (per admission). The prevalence rate of specific diseases varied by language group, with the exception of infrequent diseases (i.e., AMI, Asthma, Crohn's disease, osteoporosis, and rheumatoid arthritis). Specifically, Francophones exhibited higher rates of most diseases; however, mental illness was more common among Anglophones and the rate of diabetes was highest among Allophones.
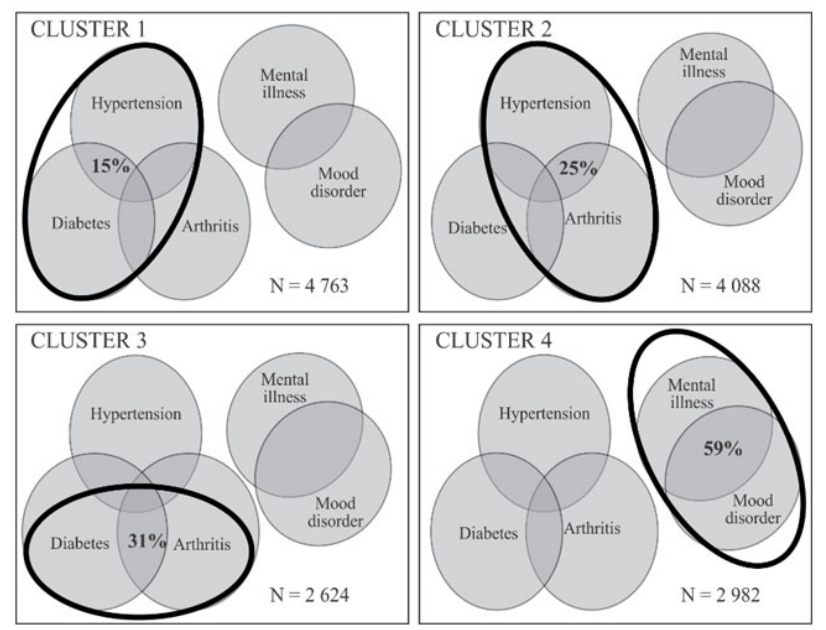

Figure 1. Common cluster profiles of chronic conditions for all services (inpatient, ED, day surgery) via Method 1 and 2 (proportion of patients [\%] in each cluster who did not have any additional chronic conditions are indicated in bold font)

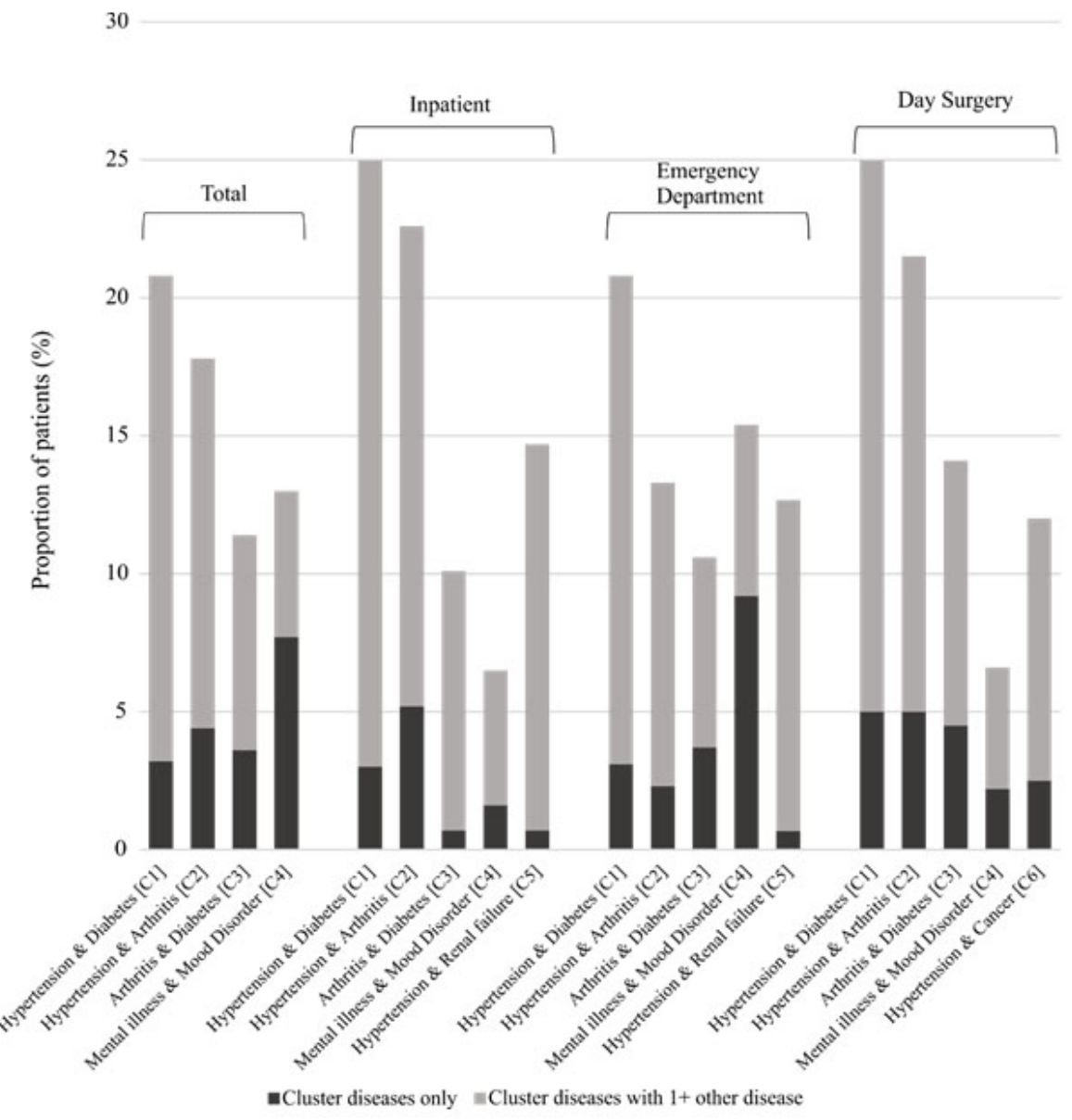

Figure 2. Proportion of patients with identified clusters (C) of chronic conditions by hospital service 
Table 2. Descriptive statistics and comparison of patients with multimorbidity by language group

\begin{tabular}{|c|c|c|c|c|c|c|c|}
\hline \multirow{2}{*}{ Variables } & \multicolumn{2}{|c|}{ Francophone } & \multicolumn{2}{|c|}{ Anglophone } & \multicolumn{2}{|c|}{ Allophone (other) } & \multirow{2}{*}{ p-values } \\
\hline & $\mathbf{N}$ (mean) & $\%(S D)$ & $\mathbf{N}$ (mean) & $\%(S D)$ & $\mathbf{N}$ (mean) & $\%(S D)$ & \\
\hline Chronic conditions (count) & & & & & & & $<.001$ \\
\hline $1^{1}$ & 15,865 & $59.1 \%^{a}$ & 16,766 & $62.7 \%^{b}$ & 3,527 & $65.5 \%^{c}$ & \\
\hline 2 & 5,024 & $18.7 \%$ & 5,049 & $18.9 \%$ & 967 & $17.9 \%$ & \\
\hline 3 & 2,549 & $9.5 \%{ }^{\mathrm{a}}$ & 2,315 & $8.7 \%^{\mathrm{b}}$ & 445 & $8.3 \%^{\mathrm{b}}$ & \\
\hline 4 & 1,504 & $5.6 \%{ }^{\mathrm{a}}$ & 1,261 & $4.7 \%^{\mathrm{b}}$ & 216 & $4.0 \%^{\mathrm{b}}$ & \\
\hline 5 & 867 & $3.2 \%{ }^{\mathrm{a}}$ & 656 & $2.5 \%^{\mathrm{b}}$ & 112 & $2.1 \%^{\mathrm{b}}$ & \\
\hline $6+$ & 1,055 & $3.9 \%^{\mathrm{a}}$ & 701 & $2.6 \%^{\mathrm{b}}$ & 122 & $2.3 \%^{\mathrm{b}}$ & \\
\hline Multimorbidity (2+) & 10,999 & $40.9 \%$ & 9,982 & $37.3 \%$ & 1,862 & $34.6 \%$ & \\
\hline Total per patient & $3.23^{\mathrm{a}}$ & 1.61 & $3.02^{\mathrm{b}}$ & 1.43 & $2.97^{\mathrm{b}}$ & 1.41 & $<.001$ \\
\hline Age (year 1) & $65.72^{\mathrm{a}}$ & 17.22 & $61.96^{\mathrm{b}}$ & 19.22 & $64.52^{\mathrm{c}}$ & 17.15 & $<.001$ \\
\hline \multicolumn{8}{|l|}{ Gender } \\
\hline Female & 5,916 & $53.8 \%^{\mathrm{a}}$ & 5,145 & $51.5 \%^{\mathrm{b}}$ & 1,012 & $54.4 \%^{\mathrm{ab}}$ & $<.001$ \\
\hline \multicolumn{8}{|l|}{ Language } \\
\hline Francophone & 10,999 & $48.0 \%^{3}$ & - & & & & \\
\hline Anglophone & - & - & 9,982 & $43.5 \%^{3}$ & - & - & \\
\hline Other language & - & - & - & - & 1,862 & $8.1 \%^{3}$ & \\
\hline \multicolumn{8}{|l|}{ ED visits (5 years) } \\
\hline $\mathrm{N}$ & 9,529 & $86.6 \%^{\mathrm{a}}$ & 8,091 & $81.1 \%^{\mathrm{b}}$ & 1,607 & $86.3 \%^{\mathrm{a}}$ & $<.001$ \\
\hline Count total & 36,600 & $49.8 \%^{3}$ & 30,788 & $41.9 \%^{3}$ & 5,937 & $8.1 \%^{3}$ & - \\
\hline Per patient & 3.84 & 4.33 & 3.81 & 5.25 & 3.69 & 3.73 & NS \\
\hline \multicolumn{8}{|l|}{ Day surgery ( 5 years) } \\
\hline $\mathrm{N}$ & 3,916 & $35.6 \%{ }^{\mathrm{a}}$ & 2,497 & $25.0 \%^{\mathrm{b}}$ & 502 & $27.0 \%^{\mathrm{b}}$ & $<.001$ \\
\hline Count total & 8,178 & $58.8 \%^{3}$ & 4,671 & $33.6 \%^{3}$ & 1,062 & $7.6 \%^{3}$ & \\
\hline Per patient & $2.09^{\mathrm{a}}$ & $2.00^{\mathrm{a}}$ & $1.87 \mathrm{~b}$ & $1.68^{\mathrm{b}}$ & $2.11 \mathrm{a}$ & $2.22^{\mathrm{a}}$ & $<.001$ \\
\hline Admitted $\geq 1$ time $^{2}$ & 6,310 & $66.2 \%^{\mathrm{a}}$ & 5,431 & $67.1 \%^{\mathrm{a}}$ & 929 & $57.8 \%{ }^{\mathrm{b}}$ & $<.001$ \\
\hline \multicolumn{8}{|l|}{ Hospitalizations (5 years) } \\
\hline $\mathrm{N}$ & 8,273 & $75.2 \%^{\mathrm{a}}$ & 7,345 & $73.6 \%^{\mathrm{b}}$ & 1,284 & $69.0 \%{ }^{c}$ & $<.001$ \\
\hline Count total & 13,997 & $50.6 \%^{3}$ & 11,595 & $41.9 \%^{3}$ & 1,984 & $7.2 \%^{3}$ & - \\
\hline Count per patient & 1.69 & $1.31^{\mathrm{a}}$ & 1.58 & $1.20^{\mathrm{b}}$ & 1.54 & $1.11^{\mathrm{b}}$ & $<.001$ \\
\hline Avg acute LOS/visit (days) & 6.77 & 7.22 & 6.65 & 8.68 & 6.93 & 8.51 & .421 \\
\hline Death (5 years) & 772 & $7.0 \%$ & 629 & $6.3 \%$ & 117 & $6.3 \%$ & .092 \\
\hline \multicolumn{8}{|l|}{ Chronic disease } \\
\hline AMI & 570 & $5.2 \%$ & 475 & $4.8 \%$ & 87 & $4.7 \%$ & .310 \\
\hline Arthritis & 3,889 & $35.4 \%^{\mathrm{a}}$ & 3,337 & $33.4 \%^{\mathrm{b}}$ & 687 & $36.9 \% \%^{\mathrm{a}}$ & .001 \\
\hline Asthma & 469 & $4.3 \%$ & 403 & $4.0 \%$ & 67 & $3.6 \%$ & .362 \\
\hline Cancer & 1,465 & $13.3 \%^{\mathrm{a}}$ & 1,027 & $10.3 \%^{\mathrm{b}}$ & 207 & $11.1 \%{ }^{\mathrm{b}}$ & $<.001$ \\
\hline Cardiac arrhythmia & 1,921 & $17.5 \%^{\mathrm{a}}$ & 1,606 & $16.1 \%^{\mathrm{b}}$ & 297 & $16.0 \%^{\text {ab }}$ & .018 \\
\hline $\mathrm{CHF}$ & 1,539 & $14.0 \%^{\mathrm{a}}$ & 1,075 & $10.8 \%^{\mathrm{b}}$ & 232 & $12.5 \%^{\mathrm{ab}}$ & $<.001$ \\
\hline COPD & 1,876 & $17.1 \%^{\mathrm{a}}$ & 1,331 & $13.3 \%^{\mathrm{b}}$ & 147 & $7.9 \%^{\mathrm{c}}$ & $<.001$ \\
\hline Coronary syndrome & 1,589 & $14.5 \%^{\mathrm{a}}$ & 1,198 & $12.0 \%^{\mathrm{b}}$ & 233 & $12.5 \%$ ab & $<.001$ \\
\hline Crohn's disease & 115 & $1.1 \%$ & 107 & $1.1 \%$ & 15 & $0.8 \%$ & .578 \\
\hline Dementia & 1,253 & $11.4 \%^{\mathrm{a}}$ & 1,035 & $10.4 \%^{\mathrm{ab}}$ & 176 & $9.5 \%^{\mathrm{b}}$ & .009 \\
\hline Diabetes & 4,294 & $39.0 \%{ }^{\mathrm{a}}$ & 3,351 & $33.6 \%^{\mathrm{b}}$ & 848 & $45.5 \%^{\mathrm{c}}$ & $<.001$ \\
\hline Hypertension & 5,856 & $53.2 \%^{\mathrm{a}}$ & 4,778 & $47.9 \%^{\mathrm{b}}$ & 1,019 & $54.7 \%^{\mathrm{a}}$ & $<.001$ \\
\hline Mental illness & 2,639 & $24.0 \%{ }^{\mathrm{a}}$ & 3,181 & $31.9 \%^{\mathrm{b}}$ & 381 & $20.5 \%^{\mathrm{c}}$ & $<.001$ \\
\hline Mood disorder & 2,418 & $22.0 \%^{\mathrm{a}}$ & 2,241 & $22.5 \%^{\mathrm{b}}$ & 351 & $18.9 \%^{\mathrm{c}}$ & $<.001$ \\
\hline Obesity & 1,435 & $13.1 \%^{\mathrm{a}}$ & 1,283 & $12.89 \%^{\mathrm{a}}$ & 193 & $10.4 \%^{\mathrm{b}}$ & .005 \\
\hline Osteoporosis & 263 & $2.4 \%$ & 203 & $2.0 \%$ & 36 & $1.3 \%$ & .152 \\
\hline Renal failure & 1,998 & $18.2 \%^{\mathrm{a}}$ & 1,650 & $16.5 \%^{\mathrm{b}}$ & 306 & $16.4 \%^{\mathrm{ab}}$ & .004 \\
\hline Rheumatoid arthritis & 105 & $0.9 \%$ & 93 & $0.9 \%$ & 16 & $0.9 \%$ & .923 \\
\hline Sleep apnea & 1,167 & $10.6 \%^{\mathrm{a}}$ & 1,155 & $11.6 \%^{\mathrm{a}}$ & 134 & $7.2 \%^{\mathrm{b}}$ & $<.001$ \\
\hline Stroke & 617 & $5.6 \%^{\mathrm{a}}$ & 462 & $4.6 \%^{b}$ & 103 & $5.5 \%^{\mathrm{ab}}$ & .005 \\
\hline
\end{tabular}

Note. $\mathrm{N}=$ Number of patients (cases); Count = Number of events; LOS = Length of stay; ED = Emergency department; Avg = Average; AMI = Acute myocardial infarction; CHF = Congestive heart failure; $\mathrm{COPD}=$ Chronic obstructive pulmonary disease; With the exception of chronic condition counts and variables labeled "total count", the denominator for the proportions in each column is the total number of patients with multimorbidity in each language group (bold font). ${ }^{\mathrm{a}, \mathrm{b}, \mathrm{c}}$ Each letter subscript denotes a subset of language group categories whose column proportions do not differ significantly from each other at the $p<.05$ level. ${ }^{1}$ Patients with a single chronic condition were excluded from all other variable statistics and analyses in this table, with the exception of disease count proportions. ${ }^{2} \mathrm{Admitted} \geq 1$ times as inpatient from ED or day surgery; this value was taken from the NACRS database and is distinct from the number of hospitalizations extracted from DAD. ${ }^{3}$ Denominator for proportion represents total population (across all linguistic groups). 
Table 3. Adjusted models for the number of chronic diseases by service type, acute LOS per admission for hospitalized patients (inpatients), and total ED visits

\begin{tabular}{|c|c|c|c|c|c|c|c|}
\hline \multirow{2}{*}{ Model/Variable } & \multirow{2}{*}{ Parameter } & \multicolumn{3}{|c|}{ Hospitalized patients } & \multicolumn{3}{|c|}{ ED patients } \\
\hline & & Estimate & SE & $p$-value & Estimate & SE & $p$-value \\
\hline \multicolumn{8}{|c|}{ Chronic condition count $^{1}$} \\
\hline Age & NA & 0.007 & 0.001 & $<.001$ & 0.009 & $<0.001$ & $<.001$ \\
\hline Gender-Female & Male & 0.029 & 0.176 & .100 & 0.030 & 0.017 & .073 \\
\hline \multirow[t]{2}{*}{ Language-English } & French & 0.051 & 0.018 & .006 & 0.019 & 0.018 & .276 \\
\hline & Other & -0.15 & 0.035 & .657 & -0.049 & 0.032 & .121 \\
\hline \multicolumn{8}{|l|}{ Acute LOS ${ }^{2}$} \\
\hline Age & NA & 0.090 & 0.004 & $<.001$ & - & - & - \\
\hline Gender-Female & Male & -0.149 & 0.119 & .210 & - & - & - \\
\hline Condition count & NA & 0.833 & 0.037 & $<.001$ & - & - & - \\
\hline \multirow[t]{2}{*}{ Language-English } & French & -0.314 & 0.123 & .011 & - & - & - \\
\hline & Other & 0.101 & 0.232 & .662 & - & - & - \\
\hline \multicolumn{8}{|l|}{ ED visits ${ }^{1}$} \\
\hline Age & NA & - & - & - & -0.013 & 0.001 & $<.001$ \\
\hline Gender-Female & Male & - & - & - & -0.072 & 0.016 & $<.001$ \\
\hline Condition count & NA & - & - & - & 0.199 & 0.005 & $<.001$ \\
\hline \multirow[t]{2}{*}{ Language-English } & French & - & - & - & 0.033 & 0.017 & .054 \\
\hline & Other & - & - & - & 0.049 & 0.031 & .115 \\
\hline
\end{tabular}

Note. $\mathrm{ED}=$ Emergency department; $\mathrm{SE}=$ Standard error (estimate), $\mathrm{NA}=$ Not applicable; $\mathrm{LOS}=$ Length of stay. ${ }^{1}$ Model uses a negative binomial distribution (parameter represents difference in the log of expected counts). ${ }^{2}$ Model is a multiple regression (presence of variable changes the LOS by the parameter estimate)

\subsection{Predicting multimorbidity and service use}

In the adjusted regression models presented in Table 3, age was a significant predictor of degree of multimorbidity (i.e., number of conditions), LOS, and number of ED visits. The influence of gender on degree of multimorbidity was negligible, though males had fewer ED visits $(p<.0001)$. Multimorbidity was significantly associated with LOS and frequency of ED visits $(p<.001)$. Adjusted models showed that compared to Anglophone inpatients, Francophone inpatients had significantly more comorbid diseases $(p=.006)$. After adjusting for age, gender, and number of chronic conditions, Francophone compared to Anglophone inpatients had a significantly shorter acute LOS on average $(p=.011)$.

\section{Discussion}

\subsection{Summary}

The objective of this study was to examine clusters of multimorbidity at a bilingual academic hospital in Ontario, Canada across three services, namely inpatient care, ED, and day surgery, and across language groups. Documenting multimorbidity profiles for patients who receive different types of services can inform treatment decisions and lead to more accurate prognoses of acute conditions, and better overall management of concurrent and underlying chronic diseases. ${ }^{[20]}$ Such insights are particularly timely given that healthcare systems tend to be oriented towards treating single conditions. ${ }^{[23,31]}$

The results of this study are novel and address a research gap, particularly in Canada, in terms of describing profiles of mul- timorbidity for different services in the hospital setting. ${ }^{[17,19]}$ Expected findings included the widespread prevalence of hypertension and arthritis, and the higher proportions of six or more chronic diseases among inpatients. Certain chronic diseases were more discernible by service type, such as the higher prevalence of comorbid cancer in day surgery patients. In addition, chronic diseases such as cancer, CHF, and diabetes were more prevalent in Francophone patients. The most common combinations of chronic diseases across all patient groups included hypertension, diabetes, and arthritis. Certain clusters of multimorbidity were more or less likely to be associated with additional diagnoses. For example, mental illness and mood disorders jointly showed a lower indication of additional morbidity.

\subsection{Prevalence and population}

The observed rates of chronic diseases and comorbidity patterns were partly a function of how and where this study was conducted, including the specific services offered at this hospital. For instance, the high prevalence of cancer in day surgery patients was expected given a high volume of colonoscopies conducted in the context of cancer screening at this hospital. Similarly, orthopedic surgeries account for a large proportion (40\%) of the surgical case load at this hospital; hence, arthritic patients made up a large volume of inpatient stays. Compared to other investigations, ${ }^{[16,32]}$ hypertension was much more prevalent among inpatients and the rate of mood disorders was significantly lower. Given the unique sample and study design, caution is required in drawing parallels to other studies, for instance studies that 
excluded surgical cases and conditions such as arthritis, ${ }^{[10,17]}$ and epidemiological studies that used primary care consultations and population-based administrative data or that did not exclude single disease profiles. ${ }^{[16,32]}$

Nonetheless, our findings are consistent with others regarding the burden of hypertension among patients with multimorbidity. ${ }^{[17,33]}$ There is evidence that hypertension is the most significant risk factors in developing cardiovascular disease and that over three-quarters of patients with hypertension have at least one other chronic disease, leading to significant increases in medical costs. ${ }^{[2,34,35]}$ In this study, hypertension was particularly common among day surgery patients. As one explanation, hypertension increases the risk of common medical conditions such as cataract, which is often treated as a same-day procedure. ${ }^{[36]}$ Still, our study did not examine disease trajectories over time, thus we cannot make inferences about the risks of developing comorbid conditions or the likelihood of requiring certain treatments.

On the other hand, we saw a low prevalence of diseases such as asthma across patient groups, and in comparison to other studies. Asthma tends to be more prevalent in studies that include younger individuals (i.e., < 18 years). ${ }^{[3]}$ Moreover, asthma may be one of several conditions that are more readily managed in primary care rather than acute care hospitals. ${ }^{[37]}$ Although asthma is a common condition among Canadians, it also appears to be less frequently associated with other conditions, ${ }^{[38]}$ which may be particularly true among older populations.

\subsection{Demographic factors}

It is important to consider the influence of demographic factors in documenting multimorbidity. Although studies have found that individuals with $\leq 3$ diseases are more likely to be female, ${ }^{[9]}$ we did not see a significant effect for gender. Gender can, however, interact with multimorbidity to influence hospitalization patterns, and should be considered in personcentered approaches. ${ }^{[16]}$ Consistent with other studies, the prevalence of multimorbidity increased significantly with age. ${ }^{[2,3,31,39]}$ This may help to explain, in part, the lower rate of other chronic diseases found in the mental health/mood disorder cluster (i.e., younger age group), although this was not examined statistically. Still, focusing solely on the elderly can underestimate the total burden of multimorbidity on the healthcare system. ${ }^{[31]}$ This may circumvent prevention efforts aimed at reducing the rate at which younger people progress from one chronic disease to multiple diseases. Moreover, in its relationship with multimorbidity, age can interact with several social factors that perpetuate inequalities in healthcare. Specifically, studies support a positive association between multimorbidity, socioeconomic status and material deprivation, and poorer health outcomes. ${ }^{[9,31,40]}$

The current study also examined the influence of language groups. Francophones were overrepresented in day surgery care, as expected given the hospital's catchment area, location, and patient tendencies to seek care in their first language. While multimorbidity clusters for Anglophone and Allophone patients were relatively similar, consistent with past research we found higher rates of most chronic diseases among Francophone patients, including cancer, CHF, COPD, coronary syndrome and obesity. ${ }^{[30]}$ Our results also indicated that Francophone patients visiting this hospital had significantly more comorbid conditions after adjusting for age and gender, and thus the fact that Francophone patients were older did not alone account for the greater burden of disease, findings that are consistent with the health risk profile of Francophones compared to Anglophones in Ontario. ${ }^{[29,30]}$ It is possible that Francophones in Ontario face more barriers to accessing healthcare services and in a timely fashion, and they may be more likely to engage in behaviours that put them at great risk of chronic health conditions (e.g., smoking and sedentary lifestyle). However, we did not control for sociodemographic and lifestyle factors nor the scope of healthcare received, therefore we can only speculate regarding the source of these patterns. Further dissection of unique disease profiles across language and cultural groups, and their resource needs, could help this institution improve the way it organizes and delivers its services.

\subsection{Resource utilization and planning}

Among patients with established cardiovascular disease, Glynn and colleagues ${ }^{[41]}$ showed that level of comorbidity, especially with diabetes or chronic kidney disease, was an independent predictor of prognosis and mortality. In the present study, rates of AMI, cardiac arrhythmia, and stroke were relatively low and similar across services, which may be unique compared to other acute care hospitals. As this hospital's cardiology program is relatively small, many cardiac cases are referred to community care or more specialized institutions. Still, knowledge of the incidence of cardiovascular diseases and associated morbidity may be useful for outpatient management and a better alignment of services. There is evidence in Ontario that patients with serious comorbidities (e.g., stroke, renal failure) are less likely to obtain follow-up care and that only half of patients with a new diagnosis of atrial fibrillation, heart failure, and hypertension are seen within a week of ED discharge. ${ }^{[42]}$ Unfortunately, mismanagement of healthcare services combined with escalating rates of chronic diseases can contribute to a cycle of increased morbidity risk and intensifying healthcare needs.

The relationship between degree of comorbidity and resource 
utilization was an expected findings. Namely, the incidence of six or more diseases was greater among inpatients and the number of diseases was significantly associated with a longer LOS and more ED visits. However, it is important to consider factors beyond disease count as there is evidence that a relatively large number of ED visits stem from a small proportion of individuals. ${ }^{[32,43]}$ Studies of frequent ED users have shown that they are more likely to experience poor physical and mental health as well as problems with substance use. $^{[44,45]}$

\subsection{The mental health factor}

Our findings revealed that the prevalence of a mental health condition was twice as high for patients visiting the ED compared to day surgery patients, and 1.5 times higher compared to inpatients. These findings are consistent with research showing that even after controlling for variables such as sex, age, poverty status, and alcohol use, adults with multimorbidity and psychological distress were more likely to use the ED than those not experiencing distress. ${ }^{[46]}$ Health administrators can use this type of information to coordinate staff and resources to optimally evaluate and respond to patients with diverse physical and mental health symptom profiles. With evidence that up to half of high-cost patients have a diagnosed mental health condition, ${ }^{[22]}$ offering integrated and coordinated physical-mental disease management across hospital sectors and community services carries important financial implications. More studies are needed to address how community resources and appropriate post-ED follow-up in primary care can be optimized in conjunction with acute care for patients with comorbid mental health conditions.

Though less pronounced in this study, mood disorders have been shown to be highly prevalent in patients with multimorbidity, ${ }^{[31]}$ consistent with evidence regarding the relationship between symptoms of depression, anxiety, and chronic physical diseases such as diabetes and COPD. ${ }^{[47,48]}$ Although up to one in four people with diabetes are at risk of developing clinically significant depression, ${ }^{[49]}$ in this study Allophones and Francophones had the highest rate of diabetes and other chronic diseases, but they had lower rates of mood disorders, suggesting that other cultural and linguistic factors may be involved. Notwithstanding the influence of underlying sociodemographic and clinical factors, it is possible that underdiagnosing and underreporting could have led to lower observed rates of mood and mental health diagnoses.

\subsection{Limitations}

Data were extracted and analyzed from only two administrative databases for this hospital: inpatient and ambulatory care. There may be limitations with respect to the breadth of data collected in these databases, as comorbidities that are well managed and medically stable, and not related to the patient visit, could be missing from the documentation. In future studies, the fidelity of hospital documentation procedures for multimorbidity may require further scrutiny. As we did not examine patient data for OMHRS that collects data for mental health inpatient services, our findings likely underestimate the burden of chronic mental health and mood disorders and the prevalence of physical-mental combinations. In addition, we did not compare patients with multimorbidity to those with a single disease to identify specific risk profiles. Moreover, the design of this study was not suited to conducting predictive analyses, and thus we did not examine the development and evolution of multimorbidity over time. Finally, given the unique nature of this bilingual hospital in terms of clientele and areas of specialty, the results may not generalize to other hospitals and services.

Future studies are needed to further understand the underlying pathophysiological and lifestyle (e.g., diet, smoking) mechanisms of multimorbidity, especially multi-system and mind-body interactions. More research is needed to better understand how to deliver comprehensive and patient-centered care across hospital services to reduce the burden of care for patients with multimorbidity.

\section{Conclusions}

The findings of this study revealed that the prevalence and configuration of multimorbidity at an acute care hospital differed between inpatients and those visiting the ED or receiving day surgery. In addition, the prevalence of multimorbidity was greater among Francophone compared to Anglophone and Allophones patients. The results contribute to a growing body of research to better understand clusters of multimorbidity in order to improve the overall efficiency and quality of healthcare services by providing more tailored care. Overall, better detection of multimorbidity, and an understanding of patients' unique needs, are necessary to deliver patient-centered services across the continuum of care. ${ }^{[50]}$ The methods used in this study may serve as an example for researchers and administrators from other hospitals seeking to address multimorbidity variability in different patient groups, and the findings may offer preliminary insights regarding the most common chronic diseases that tend to cluster together and require coordinated care. At this particular hospital, the findings have spearheaded additional studies and have been disseminated to clinicians and administrators to better target multimorbidity at the practice and policy levels.

\section{CONFlicts of InTEREST Disclosure}

The authors declare they have no conflicts of interest. 


\section{REFERENCES}

[1] World Health Organization. Health statistics and information systems: projections of mortality and causes of death, 2015 and 2030 [Internet]. 2015 [cited 2020 Sep 22]. Available from: http://www. who.int/ healthinfo/global_burden_disease/projections/en/

[2] Barnett K, Mercer SW, Norbury M, et al. Epidemiology of multimorbidity and implications for health care, research, and medical education: a cross-sectional study. The Lancet. 2012; 380: 37-43. https://doi.org/10.1016/S0140-6736(12)60240-2

[3] Koné Pefoyo AJ, Bronskill SE, Gruneir A, et al. The increasing burden and complexity of multimorbidity. BMC Public Health. 2015 15: 415. PMid: 25903064. https://doi.org/10.1186/s12889 $-015-1733-2$

[4] van Oostrom SH, Picavet HSJ, de Bruin SR, et al. Multimorbidity of chronic diseases and health care utilization in general practice. BMC Fam Pract. 2014; 15: 61. PMid: 24708798. https: //doi.org/10.1186/1471-2296-15-61

[5] Bähler C, Huber CA, Brüngger B, et al. Multimorbidity, health care utilization and costs in an elderly community-dwelling population: a claims data based observational study. BMC Health Serv Res. 2015 15: 23. PMid: 25609174. https ://doi .org/10.1186/s12913-0 15-0698-2

[6] Wang L, Si L, Cocker F, et al. A systematic review of cost-of-illness studies of multimorbidity. Appl Health Econ Health Policy. 2018; 16 15-29. PMid: 28856585. https ://doi .org/10.1007/s40258-0 17-0346-6

[7] Kingston A, Robinson L, Booth H, et al. Projections of multimorbidity in the older population in England to 2035: estimates from the Population Ageing and Care Simulation (PACSim) model. Age Ageing. 2018; 47: 374-380. PMid: 29370339. https://doi . org/10.1093/ageing/afx201

[8] Wu S, Green A. Projection of chronic disease prevalence and cost inflation. Washington, DC: RAND Health; 2000.

[9] Roberts KC, Rao DP, Bennett TL, et al. Prevalence and patterns of chronic disease multimorbidity and associated determinants in Canada. Health Promot Chronic Dis Prev Can Res Policy Pract. 2015; 35: 87-94. PMid: 26302227. https ://doi.org/10. 24095 /hpcdp.35.6.01

[10] Feely A, Lix L, Reimer K. Estimating multimorbidity prevalence with the Canadian Chronic Disease Surveillance System. Health Promot Chronic Dis Prev Can Res Policy Pract. 2017; 37: 215-222. PMid: 28703703. https://doi.org/10.24095/hpcdp.37.7.02

[11] Xu X, Mishra GD, Jones M. Mapping the global research landscape and knowledge gaps on multimorbidity: a bibliometric study. J Glob Health. 2017; 7: 010414. PMid: 28685036. https ://doi.org/10 .7189 /jogh.07.010414

[12] Diederichs C, Berger K, Bartels DB. The measurement of multiple chronic diseases-A systematic review on existing multimorbidity indices. J Gerontol Ser A. 2011; 66A: 301-311. PMid: 21112963. https://doi.org/10.1093/gerona/glq208

[13] Prados-Torres A, Calderón-Larrañaga A, Hancco-Saavedra J, et al. Multimorbidity patterns: a systematic review. J Clin Epidemiol. 2014; 67: 254-266. PMid: 24472295. https://doi.org/10.1016/j jclinepi.2013.09.021

[14] Ajmera M, Wilkins TL, Findley PA, et al. Multimorbidity, mental illness, and quality of care: Preventable hospitalizations among Medicare beneficiaries. Int J Fam Med [Internet]. 2012 [cited 2018 Sep 13]; 2012. PMid: 23320168. Available from: https ://www.ncbi .nlm.nih.gov/pmc/articles/PMC3539324/

[15] Fortin M, Bravo G, Hudon C, et al. Prevalence of multimorbidity among adults seen in family practice. Ann Fam Med. 2005; 3: 223 228. PMid: 15928225. https://doi.org/10.1370/afm. 272
[16] Gruneir A, Bronskill SE, Maxwell CJ, et al. The association between multimorbidity and hospitalization is modified by individual demographics and physician continuity of care: a retrospective cohort study. BMC Health Serv Res. 2016; 16: 154. PMid: 27122051. https ://doi.org/10.1186/s12913-016-1415-5

[17] Schneider F, Kaplan V, Rodak R, et al. Prevalence of multimorbidity in medical inpatients. Swiss Med Wkly. 2012; 142: w13533. PMid: 22407848. https://doi.org/10.4414/smw . 2012.13533

[18] Walker AE. Multiple chronic diseases and quality of life: patterns emerging from a large national sample, Australia. Chronic Illn. 2007; 3: 202-218. PMid: 18083677. https://doi.org/10.1177/1742 395307081504

[19] Steinman MA, Auerbach AD. Managing chronic disease in hospitalized patients. JAMA Intern Med. 2013; 173: 1857-1858. PMid: 23921959. https://doi.org/10.1001/jamainternmed. 2013 .9511

[20] Buurman BM, Frenkel WJ, Abu-Hanna A, et al. Acute and chronic diseases as part of multimorbidity in acutely hospitalized older patients. Eur J Intern Med. 2016; 27: 68-75. PMid: 26477016 https://doi.org/10.1016/j.ejim.2015.09.021

[21] Chan DK, Chong R, Basilikas J, et al. Survey of major chronic illnesses and hospital admissions via the emergency department in a randomized older population in Randwick, Australia. Emerg Med. 2002; 14: 387-392. PMid: 12534481. https://doi.org/10.104 6/j.1442-2026.2002.00343.x

[22] Zulman DM, Pal Chee C, Wagner TH, et al. Multimorbidity and healthcare utilisation among high-cost patients in the US Veterans Affairs Health Care System. BMJ Open. 2015; 5: e007771. PMid: 25882486. https://doi.org/10.1136/bmjopen-2015-00777 1

[23] Boyd CM, Fortin M. Future of multimorbidity research: How should understanding of multimorbidity inform health system design? Public Health Rev. 2010; 32: 451-474. https ://doi.org/10.1007/ BF03391611

[24] Cabassa LJ, Humensky J, Druss B, et al. Do race, ethnicity, and psychiatric diagnoses matter in the prevalence of multiple chronic medical conditions? Med Care. 2013; 51: 540-547. PMid: 23552429 https://doi.org/10.1097/MLR.0b013e31828dbb19

[25] Shadmi E. Multimorbidity and equity in health. Int J Equity Health. 2013; 12: 59. PMid: 23961952. https://doi.org/10.1186/14 75-9276-12-59

[26] Statistics Canada. Annual demographic estimates: Canada, provinces and territories (Catalogue number 91-215-x2013000) [Internet]. Ottawa, ON: Statistics Canada; 2015. Available from: http://www . statcan.gc.ca/pub/91-215-x/91-215-x2013000-eng.htm

[27] Bouchard L, Sedigh G, Batal M, et al. Language as an important determinant of povery in the aging francophone minority population in Canada. Int J Aging Soc. 2013; 2: 61-76. https ://doi .org/10 .18848/2160-1909/CGP/v02i04/35223

[28] Bouchard L, Batal M, Imbeault P, et al. Précarité des populations francophones âgées vivant en situation linguistique minoritaire. Minor Linguist Soc Linguist Minor Soc. 2015; 66-81. https : //doi.org/10.7202/1033190ar

[29] Bélanger M, Bouchard L, Gaboury I, et al. Perceived health status of Francophones and Anglophones in an officially bilingual Canadian province. Can J Public Health. 2011; 102: 122-126. PMid: 21608384 https : //doi.org/10.1007/BF03404160

[30] Picard L, Allaire G. Second report on the Health of Francophones in Ontario [Internet]. Sudbury, ON: Public Health Research, Education and Development Program; 2005 [cited 2017 Nov 20]. Available from: http://opha.on.ca/getmedia/f1d12c65-95ed-494 
e-8ab7-9b6c8b556bac/HealthofFrancophones-EN . pdf . as px?ext $=. p d f$

[31] Ryan BL, Bray Jenkyn K, Shariff SZ, et al. Beyond the grey tsunami: a cross-sectional population-based study of multimorbidity in Ontario. Can J Public Health. 2018; 109: 845-854. PMid: 30022403. https ://doi.org/10.17269/s41997-018-0103-0

[32] Gruneir A, Cigsar C, Wang X, et al. Repeat emergency department visits by nursing home residents: a cohort study using health administrative data. BMC Geriatr [Internet]. 2018 [cited 2018 Oct 25]; 18. PMid: 29976135. https ://doi .org/10.1186/s12877-018 $-0854-8$

[33] Sarkar C, Dodhia H, Crompton J, et al. Hypertension: a crosssectional study of the role of multimorbidity in blood pressure control. BMC Fam Pract. 2015; 16: 98. PMid: 26248616. https: //doi.org/10.1186/s12875-015-0313-y

[34] Park C, Fang J, Hawkins NA, et al. Comorbidity status and annual total medical expenditures in U.S. hypertensive adults. Am J Prev Med. 2017; 53: S172-S181. PMid: 29153118. https: //doi.org/10.1016/j.amepre.2017.07.014

[35] Schofield P, Bawwuah F, Seed P, et al. Managing hypertension in general practice: a cross-sectional study of treatment and ethnicity. Br J Gen Pract. 2012; 62: e703-709. PMid: 23265230. https://doi.org/10.3399/bjgp12x656847

[36] Yu X, Lyu D, Dong X, et al. Hypertension and risk of cataract: A meta-analysis. PLoS ONE [Internet]. 2014 [cited 2018 Oct 23]; 9. PMid: 25474403. https://doi.org/10.1371/journal.po ne. 0114012

[37] Health and Social Care Information Centre. Quality and Outcomes Framework (QOF) 2013-14: prevalence, achievements and exceptions at region and nation level for England. Leeds: HSCIC; 2014.

[38] FitzGerald JM, Boulet L-P, McIvor RA, et al. Asthma control in Canada remains suboptimal: The Reality of Asthma Control (TRAC) Study. Can Respir J. 2006; 13: 253-259. PMid: 16896426. https ://doi .org/10.1155/2006/753083

[39] McLean G, Gunn J, Wyke S, et al. The influence of socioeconomic deprivation on multimorbidity at different ages: a cross-sectional study. Br J Gen Pract. 2014; 64: e440-e447. PMid: 24982497. https://doi.org/10.3399/bjgp14X680545

[40] Violan C, Foguet-Boreu Q, Flores-Mateo G, et al. Prevalence, determinants and patterns of multimorbidity in primary care: A aystematic review of pbservational studies. PLOS ONE. 2014; 9: e102149. PMid: 25048354. https://doi.org/10.1371/journal.pone .0102149
[41] Glynn LG, Buckley B, Reddan D, et al. Multimorbidity and risk among patients with established cardiovascular disease: a cohort study. Br J Gen Pract. 2008; 58: 488-494. PMid: 18611315. https://doi.org/10.3399/bjgp08X319459

[42] Atzema CL, Yu B, Ivers NM, et al. Predictors of obtaining follow-up care in the province of Ontario, Canada, following a new diagnosis of atrial fibrillation, heart failure, and hypertension in the emergency department. Can J Emerg Med. 2018; 20: 377-391. PMid: 28803593. https://doi.org/10.1017/cem.2017.371

[43] LaCalle E, Rabin E. Frequent users of emergency departments: the myths, the data, and the policy implications. Ann Emerg Med. 2010; 56: 42-48. https://doi.org/10.1016/j . annemergmed. 2010 .01 .032

[44] Fuda KK, Immekus R. Frequent users of Massachusetts emergency departments: a statewide analysis. Ann Emerg Med. 2006; 48: 9-16. PMid: 16781915. https ://doi.org/10.1016/j . annemergmed. 2006.03.001

[45] Vandyk AD, Harrison MB, VanDenKerkhof EG, et al. Frequent emergency department use by individuals seeking mental healthcare: a systematic search and review. Arch Psychiatr Nurs. 2013; 27 : 171178. PMid: 23915694. https://doi.org/10.1016/j . apnu. 201 3.03.001

[46] Alhussain K, Meraya AM, Sambamoorthi U. Serious psychological distress and emergency room use among adults with multimorbidity in the United States. Psychiatry J [Internet]. 2017 [cited 2019 Feb 11]; 2017. PMid: 29085831. https://doi.org/10.1155/2017 /8565186

[47] Clarke DM, Currie KC. Depression, anxiety and their relationship with chronic diseases: a review of the epidemiology, risk and treatment evidence. Med J Aust. 2009; 190: S54-S60. https : //doi.org/10.5694/j.1326-5377.2009.tb02471.x

[48] Zhang MWB, Ho RCM, Cheung MWL, et al. Prevalence of depressive symptoms in patients with chronic obstructive pulmonary disease: a systematic review, meta-analysis and meta-regression. Gen Hosp Psychiatry. 2011; 33: 217-223. PMid: 21601717. https : //doi.org/10.1016/j.genhosppsych.2011.03.009

[49] Semenkovich K, Brown ME, Svrakic DM, et al. Depression in type 2 diabetes mellitus: Prevalence, impact, and treatment. Drugs. 2015; 75: 577-587. PMid: 25851098. https://doi.org/10.1007/s4 0265-015-0347-4

[50] Bell SP, Saraf AA. Epidemiology of multimorbidity in older adults with cardiovascular disease. Clin Geriatr Med. 2016; 32: 215 226. PMid: 27113142. https://doi.org/10.1016/j.cger.2 016.01 .013 